\title{
Research on NTS Public Security Risk and Prevention and Control*
}

\author{
Qin Wei \\ Faculty of Public Security Management \\ Hubei University of Police \\ Wuhan, China 430034
}

\begin{abstract}
In today's risky society, especially in the complex context of non-traditional factors such as economic globalization, social information, and cultural diversity, the NTS-type public safety risks, such as violent terrorist incidents, information security threats, food and drug environment security risks, ecological security risks and public large-scale events have become increasingly prominent. Therefore, it is particularly important to conduct scientific social security risk assessment and improve the ability to control public security situation in the new era of informationization. This article considers how to improve the public security risk prevention preparation, monitoring and early warning, situational analysis, rescue and disposal, and comprehensive protection and other key prevention and control countermeasures from the perspectives of expounding NTS-type risk implications, risk evolution models, and government governance paths of NTS risk so as to improve our public security system and comprehensive public security capabilities.
\end{abstract}

Keywords—non-traditional; public security risks; prevention and control

\section{INTRODUCTION}

In recent years, public security incidents in our country have continued to occur, and the internal structure and external performance of the development of public security incidents are highly compatible with the "risk society theory". In order to promote public safety managers to manage and control the public safety incidents and their potential risks, it is necessary to take a comprehensive view of urban public safety risk management from the perspective of risks. With the changes in social politics and economic structure, and the advent of the era of big information data, the study of public safety risks must distinguish between traditional and non-traditional areas of risk society, risk assessment procedures, and risk evolution model accompanied by analyzing the different features of the framework.

\section{NTS PUBLIC SAFETY RISK}

Non-traditional security (NTS) refers to the security threats that human society has not encountered or rarely seen in the

*Source of the project: the approved (sponsored) project of Research Center of social security management of Hubei University of Police, the Key Research Base of the Humanities and Social Sciences in Hubei

Project name: Typical NTS risk assessment, prevention-control and case studies. past; that is, the security threats that have gradually emerged but far from the battlefield in recent years. The characteristics of non-traditional security mainly lie in: non-traditional security covers a wide range of fields, including all fields involving national security except military security, such as financial security, environmental security, information security, public health security, food and drug safety, and terrorism and the security of large-scale events in large cities, etc., which are difficult to ensure or solve by purely military means. The above-mentioned fields have strong transnationality, and at the same time, each field is interactive. As a result, a country's security problems may inspire problems in other countries or regions. And problems in one aspect may inspire other aspects of security issues, so that security issues will show a step-bystep amplification effect. China's society is currently facing severe tests of "disordered economic development, unsteady social development, abnormal social morality, unbalanced public psychology, and untrustworthy social relations." In 2016 , only $12.1 \%$ of the respondents in the China considered the social situation "unsafe" in the investigation of "China safe well-off index", and this unsafe feeling came from various risks in the new economic era. For example, the "Sanlu Poisoned Milk Powder" incident that occurred in September 2008 caused a total of 29.6 million infants with abnormal urinary tract diseases. "Food is the first necessity of the people, the safety of food is always the first", therefore, we must crack down on food and drug offenses. In recent years, the problem of illegal addition and abuse of additives in food production and processing links is still outstanding. To solve this problem, the public security organs need to pay close attention to the new situation of making and selling fake products in the electronic business platform, strengthen the risk investigation and intensify the jointly on-line and off-line strike. At the same time, the relevant departments should innovate the working mechanism against crime, and for the major trans-national cases, it should be supervised, together investigated and deeply attacked by the Ministry of Public Security. In addition, the 2013 Beijing "10. 28" Golden Water Bridge incident and the Kunming "3 1" incidents both are serious violent terrorist incidents; the stampede incident in Shanghai at the end of 2014;"the paralyzed city of Hainan marathon" in 2015, and other public safety accidents. Besides that, at about $11 \mathrm{pm}$ on June 27, 2017, a large-scale cyber security incident broke out again in Europe. European companies including the world' $\mathrm{s}$ largest advertising company, WPP, and the cyber system of 
Kiev' s airport in Ukraine were attacked. Related users were asked to pay $\$ 300$ in encrypted digital currency to unlock their computers. More than 100,000 computers in more than 100 countries and regions, including China, were attacked and infected by ransomware. The attack came from a ransomware virus named Petya. In the face of various types of NTS risks as described above, the government's safety management department should build strong awareness and strong capabilities in risk assessment and risk management and control. Since security is a stable state in which the survival and development of society is free from danger, the state can rely on its own resources to mobilize all available resources when it comes to danger or threat, whether it is from external dangers or threats or from internal dangers or threats. Corresponding measures and measures should be taken to control the dangers and ensure safety so as to put the society in a stable state free of danger or threats. In the course of governance of social security, the government and other social entities are faced with real or potential public safety risks, and this risk is accumulating to some extent. The "risk society theory" can describe and reflect the structural characteristics and internal development mechanism of China's public security risks well, providing a new theoretical perspective for our understanding of national public security governance. The new types of public safety accidents that have occurred in recent years are reminding us: the innovation of the NTS public safety risk management mechanism is imminent and an important condition for China to achieve stable and sustainable development. We need to respond to the theory of risk assessment and risk prevention and control.

\section{NTS RISK EVOLUTION MODEL}

The theory of non-traditional disaster systems is the basic theory of disaster science and it is also the basic background for discussing public security risks. Since the 1970s, scientists have conducted theoretical discussions on the general characteristics and laws of disasters on the basis of a large number of concrete disaster cases. Gradually, disaster science theories have been formed with the core paradigm of disaster system theory. Bertalanffy defined the system as an "interacting multi-element complex," pointing out the characteristics of system diversity, relevance, and integrity. According to the theory of disaster systems, the hazardformative environment include not only natural environments (such as weather, rivers, and terrain) but also social and cultural environments (such as urban population, safety facilities, and security environment).The so-called hazard factors refer to the factors that cause disasters in the hazard-hit environment, such as earthquakes, fires, large-scale group gathering activities, and international terrorist organizations. The so-called disaster-afflicted body refers to the objects that bear the disasters and it also includes the natural world, the public, and so on. The so-called "disaster loss" refers to the reduction in the amount and degradation of quality of things required for the survival and development of human beings as a result of disasters, and it is the most typical manifestation of disasters. If systemic language is used, the disaster system (D) is a complex structural system consisting of a hazard-formative environment $(\mathrm{E})$, a hazard factor $(\mathrm{H})$, and a hazard bearing body (S) so, $D_{s}=E \cap H \cap S_{\text {in "Fig. 1". In this case, disasters }}$ are the result of the interaction of various elements in nontraditional public safety disaster systems. It can be said that the three elements that make up the regional disaster system are indispensable in the formation of disaster conditions. It is only in the aspect of the development of the size of the disaster that the changes in the characteristics of each factor have a different effect on the severity of the disaster. There isn't the condition that who are the determinants or who are the secondary factors of these three elements. They are all necessary and full conditions for the formation of disasters.

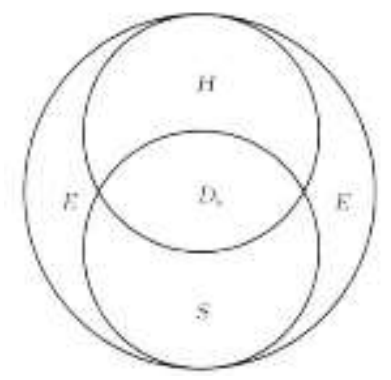

Fig. 1. The structure of non-traditional public safety risk system.

The author takes the example of stampede accidents involving people in urban gathering activities of large-scale group in non-traditional security fields. People often attribute trampling disasters to large-scale crowd gatherings. However, if we look at the theory of disaster systems, over-concentration of space populations is a disaster-causing factor, but it is only one aspect of disasters. In fact, the vulnerability of the disasterafflicted body (social public security system) is also an important cause of treading disasters. For example, the lack of sensitive public safety risk awareness, funds or ideas or technologies in the risk prevention and control facilities will result in the weak ability of public places to resist high-density crowd gathering activities and the high vulnerability of people. In response, the degree of damage to the public tends to intensify rapidly, which further increases the probability of the generation of hazard factors, and in fact it is also an "accumulation process" of vulnerability. This combined effect of the accumulation of vulnerability and hazard factors has brought tremendous pressure on the public and society in the region. When the pressure exceeds the critical value (such as the highest level of the flood control dam), public disasters will inevitably form.

Under the current background of the prominent international crime problem and the vulnerability of network information security to global attacks, the formation of public safety hazards can be divided into disaster dynamic processes (such as earthquake disaster processes ,fire processes, crime process of temporary initiation, epidemic situation, etc.) and disaster ecology processes formed by accumulation of stochastic hazards factors (such as food and drug safety accidents, global network processes, etc.) The interaction mechanism between structure and hazard factors is the key to understanding the dynamic process, and the interaction mechanism between critical value domain and ecological environment is the key to understand this process. 


\section{GOVERNMENT GOVERNANCE PATH OF NTS RISK}

In the field of non-traditional public safety, risk is essentially a threat to safety and security. When the risk turns into a real danger, the consequences are catastrophic. The reason for this is that this disastrous consequence is related to the safety of life, health, and property of the general public or most people. How to effectively protect the lives, health, and property of the general public or the majority of people and build a harmonious and stable security environment is very urgent.

\section{A. Strengthen System Engineering Centered on Social Risks}

At present, China's public safety management system implements decentralized management by industries and subsectors, and have insufficient coordination capabilities. Due to the complexity of the public security risk response and the features of cross-industry, cross-department, and crossregional, it needs to work together to achieve overall efficiency. Moreover, the public security risk response is not limited to disposal, but also includes a series of processes such as prevention, discovery, management, control, and recovery. In order to prevent evasion and misunderstanding, unclear responsibilities, and unclear responsibilities, it is necessary to establish a stable public safety management system that is government-led as a comprehensive command system to coordinate and integrate the power resources of various departments and industries, including the active participation of public and volunteers and clarify the functions, responsibilities, tasks, and relationships of public safety management. Under certain conditions, a special public safety management team can be established to prevent, dispose of and resolve public safety risks, and to control and calm conflicts and disputes caused by social contradiction. At the same time, we must strengthen the research, development, and utilization of public safety products, cultivate public safety service industries, and provide technical support for the monitoring of public safety risks.

The establishment of a public safety management mechanism should be improved, including the construction of a fair and reasonable interest distribution mechanism, a smooth interest appeal solution mechanism, a risk early warning and control mechanism, a conflict and dispute resolution mechanism, and the enhancement mechanism of public safety risk handling capability to change to all-round management or comprehensive management from emergency management and ensure the continued stability of public safety. Therefore, it is imperative to establish a public safety management system, including a multi-faceted, multi-sequential management and operation system such as decision-making and command system, organization and implementation system, technical support system, emergency warning system, material security system, information transmission system, and legal security system. These systems should be led, unified and coordinated by government, and the government should be hierarchically responsible for them, and ensure the sharing of information and resources to jointly respond to security risks. In addition, it is crucial to rely on the system governance theory to construct a three-dimensional system of government, society and market participation in the joint management of risk to improve the risk management ability of the city government and cultivate the self-regulation ability of the market and give full play to the role of the civil society in the risk management. The objectivity and inevitability of risk and risk society existence will promote the country or government to have more responsibility to strengthen the self-conscious behavior of risk response and carry out effective decision-making, and conduct top-level design from the aspects of national security governance and risk prevention and control .For example, in order to deal with national security risks, China set up a National Security Committee to plan and maintain national security concepts and ideas, put forward the view of a national security concept, and build a national security system, which shows that the country or the government takes proactive measures to deal with national security risks and plans ahead.

\section{B. Grasping the Risk Trend of NTS, Perfecting and Improving the Legal System of Public Security}

As the risk evolves from the traditional to the nontraditional era, people' s main task is to prevent and eliminate various catastrophic risks that can jeopardize or destroy humans, including food and drug safety risks, terrorist activity risks, ecological risks, and international crime risks and nuclear risks caused by the rapid development of such technologies as biotechnology and space. In legal representation, "rule of the law" and "governance of the law", in the process of advocating and implementing legal thinking and using the rule of law method to analyze and resolve emerging issues of social risks in a number of non-traditional areas, how to improve the legal perspective and improve the public safety legal system is a problem worthy of our attention. We must make early preparations in response to possible invasion of foreign enemies, terrorism, transnational crimes, piracy, and money laundering, and take preventive measures. In areas such as eco-environmental safety, food safety, and cyber information security, the state or government has introduced and formulated stringent institutional rules and prevention and punishment mechanisms. For example, the newly revised Environmental Protection Law is called "the harshest" environmental protection law in history. And it has further clarified the responsibility, made clear the responsibility, and increased the strength of the punishment unprecedentedly in order to establish a complete system of ecological civilization. Its implementation will certainly play an important role in the protection. At present, China has successively formulated the "Environmental Protection Law", "Water Pollution Prevention Law", "Food Safety Law", "Safety Production Law", "Fire Protection Law", "Road Traffic Safety Law" and "The National Security Law", the "Law of Emergency Response Act", the "Anti-Terrorism Law of People's Republic of China" and other related laws, but there is still a clear lack of legislation. For example, no ecological compensation law or information security compensation law has yet been established; the procedural content of laws that have been enacted is lacking; the legal regulation of rights relief is still weak; the principle provisions are larger than the operational regulations. The existence of these problems is difficult to meet and handle the needs of public security risks. In the course of improving and perfecting the public safety legal system, new laws such as the "People's 
Republic of China Police Law", ecological compensation law, information security compensation law, etc. shall be formulated as soon as possible, and the procedural content, rights relief content, and other laws in the existing regulations shall be improved. In addition, it is proposed to formulate a unified "Public Security Law" to clarify the functions of public safety, the principles followed, the management system, mutual relations, responsibilities of the government and various departments, powers and responsibilities, procedural rules, and rights relief to further standardize the public safety management practices and provide a strong legal system guarantee for public safety management.

\section{Pay Attention to the Compound and Collaborative Management of the Combination of "Control" and "Prevention and Control" but not Just"Control"}

Public safety is related to the life, health, and property safety of the public or the majority of people. It is related to the interests of social organizations and every member of society. Public safety management is not only the management of the government, but also the management of the public. It is the common cause and the common responsibility of the whole society. Public safety management should integrate social forces. In particular, it should give full play to the role of nongovernmental organizations or non-profit organizations, such as Red Cross, charities, religious organizations, trade associations, volunteer organizations, private companies, etc., and coordinate and cooperate in governance. The approaches and measures for public security management to integrate social forces and carry out collaborative governance: the first is to increase the sense of risk and safety awareness of the public and citizens so that they will maintain public safety benefits and participate in public safety management as their own tasks or as a responsibility, and it is necessary to establish the participation mechanism of the public and citizens under the leadership and coordination of the government and relevant departments. Moreover, it is crucial to institutionalize them. The second is to attach importance to the guidance and training of the public and citizens on public safety risk management and response knowledge and skills, including scenario training, risk response simulation training, characteristics of terrorism, disasters, and accidents, as well as occurrence and development patterns, self-protection and self-help methods, psychological endurance and defense capabilities, ensuring that they can participate in the orderly manner when facing public safety risks, assisting and coordinating with the government and related departments in handling and responding the risks, and finally forming a joint force. In today's society, the disposal and response of public security risks is increasingly dependent on the participation of multiple forces such as the government, the public, non-governmental organizations, citizens, and the media. The participation of multiple forces is the only way to solve the public security risks. To build a system of prevention and governance of multi-participation, which is an organic combination of the governance concept of harmonious development, the governance entity of global cooperation, and the governance approach of diversified public participation at the operational level.

\section{Methodology Should Focus on Scientific Quantitative Research}

Some public safety managers still do not recognize the nature and connotation of social risks. They believe that risks are unpredictable and non-procedural, and it is difficult to carry out effective measurement and prevention by using scientific methods. However, no matter whether social risk is attached to society as a construction or reality, it is a general trend for future risk management to measure more scientifically to improve risk prevention capability. Therefore, it is necessary to rely on quantitative research elements of natural sciences and constantly added them to the management of prevention and control, finally forming the long-term inertia.

For example, for the key technical indicators to be noted for risk prevention and control, through analysis, we believe that from the perspective of risk prevention, their key technical indicators should compose of the selected representative and comprehensive indicators, such as the "warning situation", "warning megaphone", and "warning source" and "preliminary warning control" that specifically reflect the state of public security. Moreover, these indicators can be continuously supplemented and updated according to different regions and different time requirements. In order to change the condition single warning indicator in the past, the indicators should reflect the diversified structure .They must have both quantitative and qualitative indicators; both objective and subjective indicators; both current and precursor indicators; as well as dynamic indicators relative to static conditions. The relevant departments can use the normal model comparison method, that is, through comparison, the numerical value of the maximum growth rate, the average growth rate and the minimum growth rate are obtained, so as to design the norm index in different "alarm" and "alarm limit" grade value of the "severe warning""medium warning""light warning" and "no warning" and the "warning limits". Then, by comparing the indicators during the reporting period, it is possible to determine which of the degrees of alert corresponds to the index, and then send an early warning signal for leaders to make decisions based on assessments made by professionals according to technical data and professional experience. From the perspective of risk control technology, it should be based on the degree of specialization, practicality, and intelligence of its technology. For example, it is possible to think about the research of social and public security risk prevention and control technologies based on the "Internet Plus"; research decision support technology of case and scenario fusion deductive; study the accurate release of emergency warning information and security control technology; studying largescale evacuation and refuge placement techniques in complex disaster environments; research emergency big data visualization and emergency map technology, etc.

\section{CONCLUSION}

In the face of risk and challenges, we believe that the key to prevention and control is to focus on problem orientation, not to overlook the signs of risks and risks of low probability, and not to overlook risk aggregation points and high probability events to prevent both "black swans" and "Grey rhinoceros". Through focusing on risk prevention and control, 
it is important to strive to create a safe and stable social security environment. In order to innovate and perfect a threedimensional social security prevention and control system, we should work hard to grasp the details of actual problems, strengthen the skeleton, and weave dense grids, eliminate the "obstruction" of the operation of the mechanism and the "blind spot" of public security prevention and control to open up the "last mile" for the doubled effectiveness of prevention and control system.

Specifically, we can suggest that public safety related departments pay attention to the construction of non-traditional risk prevention thinking and capabilities, such as establishing a community basic database covering community data such as people, events, land, objects, and organizations, and establish the business specifications of grid function expansion of community risk prevention and develop the grid staff equipment with fingerprint recognition, face recognition and other functions; based on big data technology and grid management technology, it is important to establish a community risk prevention platform integrating police affairs, government affairs, property management, and integrated management to realize real-time monitoring, trajectory tracking, automatic alarming, and active assistance, and to exert safety assessment, safety response, and security warning and other functions that can dynamically identify security risks and dynamically adjust social risk prevention and control strategies

\section{REFERENCES}

[1] Qiao Hui.On the Interpretation Framework of Baker's Risky Social Theory [J].Studies in Dialectics of Nature，2015(1) 乔慧. 论贝克风险 社会理论的解释框架 [J]. 自然辩证法研究, 2015(1)

[2] Cao Huimin.Research on Governance Strategy of Urban Public Security from the Perspective of Risk Society[J].Learning and Practice, 2015(3) 曹惠民. 风险社会视角下城市公共安全治理策略研究 $[\mathrm{J}]$. 学习与实 践, 2015(3)

[3] Liu Yan. Group Events of Environmental Risk and Risk Conflicts in a Transforming Society [J].Journal of Jilin University, 2010(5) 刘岩.转 型社会的环境风险群体性事件及风险冲突 $[\mathrm{J}]$. 吉林大学学报, 2010(5)

[4] Zhang Qi. The Research and Analysis of Nanjing Youth Olympic Games Security Risk Based on the Non-Traditional Security Theory[J].Journal of Nanjing Institute of Physical Education, 2011(5) 张琪. 基于非传统安全理论对南京青奥会安保风险的研究分析 [J]. 南 京体育学院学报, 2011(5)

[5] Ran Lian, Li Yibo.Public Security Governance in the Perspective of Risk Society - - Based on Political Fields [J].Journal of Zhejiang Wanli University, 2014.( 7) 再连, 李艺博. 风险社会视阈下公共安全 治理———基于政治领域视角[J].浙江万里学院学报, 2014.( 7). 